DOI: http://dx.doi.org/10.12775/ths.2015.003

\author{
Marta Sibierska \\ Center for Language Evolution Studies (CLES); \\ Department of English, Nicolaus Copernicus University \\ marta.sibierska@gmail.com
}

\title{
Play Frames in Narratives: Some Implications of Considering Storytelling Practices as Anchored in Play-Pretend
}

\begin{abstract}
This paper dwells on the trend of considering storytelling practices as anchored in play-pretend (e.g. Boyd 2009) and attempts at pointing to some of the implications of such an approach that have not so far been discussed, such as the problem of proper framing of a narrative, i.e. a story told. In order to provide the instances of possible framing designs and signals for narratives, the paper first outlines the general characteristics of play in animals that seem significant from the perspective of this very undertaking; then, it elaborates on the theory of art and storytelling - as adaptation evolved from play (cf. Boyd 2009). Subsequently, it discusses play frames and pre-play exchange, as understood, primarily, by Gregory Bateson (1972), and, finally, applies these to the study of narrative media and forms.
\end{abstract}

Keywords: play; pre-play exchange; play frame; metacommunication signal; cognitive narratology; narrative; framing narratives.

\section{Introduction}

One of the most interesting outcomes of approaching culture from a cognitive and an evolutionary standpoint is the theory of art and storytelling as an adaptation. To use Jonathan Gottschall words, "[ $\mathrm{t}$ ] is a storyteller" (Gottschall 2012: 87); man, in turn, is "the storytelling animal" (Swift in Gottschall 2012:87). Indeed, it seems that, as Christopher 
Collins puts it, "imaginative literature relies on and reactivates the deepest layers of our cognitive architecture and, in so doing, shows us the way down those neural pathways of our ancestral past" (Collins 2013: 57). What is the past of art? What is its function? In order to answer these questions, some scholars - for instance, Brian Boyd (2009) - have decided to compare the patterns for engaging in art to that of other behaviours observable in the animal kingdom, ultimately coming to the conclusion that artistic activity - inclusive of storytelling - found in humans is much connected with animal play. But even though art in general has been thoroughly analysed in the context of play, there is still little research on the exact workings of storytelling as a play activity. The purpose of this paper is, then, to point to the implications of seeing storytelling practices in humans as anchored in animal play connected with the processes of providing a proper play frame for narratives, i.e. signalling play intentions by the players.

\section{Animal Play}

Play seems to be a universal in all mammals, but also in birds, fish, and reptiles (Boyd 2009: 91). Actually, all animals that have been observed for play behaviour, proved to display it. Ethological research ${ }^{1}$, which has so far been the main source of evidence on play (Burghardt 2005: 10), is crucial for understanding play, "addressing [its] evolutionary origins" and "its associated functions" (Burghardt and Graham 2010: 394). What has been determined about play so far? Since play is difficult to define, though we intuitionally recognise it both in our own as well as in other species (Burghardt and Graham 2010: 393-394), "when it comes to making theoretical statements about what play is, we fall into silliness" (Sutton-Smith 1997: 1). In order to briefly characterise play for the purposes of this paper without falling into too much of silliness, let us first consider an example of behaviour often observed in common ravens, here described by Bern Heinrich and Rachel Smolker:

Observers from Alaskan and Northern Canadian towns routinely reported to us seeing ravens slide down steep snow covered roofs, only to fly or walk back up and repeat the slide. Ravens in our Maine aviary also roll down mounds of snow, and even do so on their backs with a stick held in the feet! David Lidstone, observing

1 Especially in non-human animals and children (Burghardt and Graham 2010: 395). 
ravens at a deer carcass in Maine during the first snow storm of the year, reported that 'at least three birds flew up to a stump on a 2-3 $\mathrm{m}$ incline, and then slid down the slope on their backs. Twice the sliding bird was holding a stick in its talons'. Gwinner (1966) reported seeing his captive ravens repeatedly sliding down a board. We see no obvious utilitarian function for sliding behavior. Perhaps it is a social display (not necessarily play) involved in securing status or mates by 'showing off' or drawing attention to themselves. (Heinrich and Smolker 1998: 36)

The phenomenon alluded to above is actually an example of what within play studies has been called 'locomotor play'. Apart from (A) locomotor play, which involves exaggerated movement, such as jumping (or sliding down roofs covered with snow), animals tend to engage in (B) manipulative play, i.e. playing with objects, and (C) social play, which embeds chasing, nipping, and so on (Burghardt 2005: 15). Importantly, both object and social play derive from locomotor play (Burghardt 2005: 15). Social play, in turn, can also contain elements of the two others (Collins 2013: 67) ${ }^{2}$. The types of play are, then, by no means independent (Burghardt 2010: 340).

The most common type of play among animals is probably pretended combat - also called "rough-and-tumble" (R\&T) play or "play-fighting" or, at least, it is the type of play that has been most frequently studied (Burghardt and Graham 2010: 395). As Gregory Bateson reports in his essay "A Theory of Play and Fantasy", when he went to the Fleishhacker Zoo in San Francisco, he "saw two young monkeys playing, i.e., engaged in an interactive sequence of which the unit actions or signals were similar to but not the same as those of combat. It was evident, even to the human observer, that the sequence as a whole was not combat, and evident to the human observer that to the participant monkeys this was "not combat"' (Bateson 1972: 185). Play thus contains two contrary premises: (1) that something is what it is (e.g. monkeys are chasing one another, putting in actual effort and energy), and (2) that the very same thing is not what it is (e.g. in this context, chasing does not indicate actual hostility), but stands for something else (cf. Collins 2013: 63-64). In other words, a play behaviour "is not and,

2 This is not the only classification present in play studies, though; Burghardt and Graham refer, for instance, to the taxonomy introduced by Fagen, in which play is divided into: "(1) solitary locomotor-rotational play; (2) object play; and (3) social play" (Fagen 1981 in Burghardt and Graham 2010: 394). Importantly, no matter to what taxonomy we stick, we have to bear in mind that "the boundaries of two or more play categories are often blurred, and individual categories are often subdivided" (Burghardt and Graham 2010: 394). 
at the same time, is what it represents to the player" (Collins 2013: 64). This cognitive split can be called, after Christopher Collins, a kind of a "magical doubleness" (2013: 64).

The "magical doubleness" alongside all the physical effort put in actions accompanying play add up to certain costs in energy and time. Moreover, playing is also connected with the risk of "injury from falls or aggressive retaliation," or "conspicuousness of play to predators" (Burghardt and Graham 2010: 399). Interestingly, despite the costs, and despite the universal character of play, as Heinrich and Smolker admit at one point of their subchapter about ravens snow-sliding, it is difficult to discern an "obvious utilitarian function" in this type of behaviour. Indeed, the crucial characteristic of play is that it is seemingly purposeless. Seemingly, for it is not the case that it serves no purpose, it is just that the purpose is not instantly observable ${ }^{3}$ (e.g. Collins 2013: 63).

Why, then, do animals play? Or, in other words, "what actually is the fun of playing?" (Huizinga 1980: 2). One of the "postponed" benefits of play is learning: perfecting particular skills and scripts (cf. Boyd 2009: 92). More specifically, Burghardt and Graham list, for instance: motor training, training for unexpected events, or instinct practice (2010: 396-398). As Brian Boyd stresses,

The more often and the more exuberantly animals play, the more they hone skills, widen repertoires, and sharpen sensitivities. Play therefore has evolved to be highly self-rewarding. Through the compulsiveness of play, animals incrementally alter muscle tone and neural wiring, strengthen and increase the processing speed of synaptic pathways, and improve their capacity and potential for performance in later, less forgiving circumstances. (Boyd 2009: 92).

It is the case, then, that - quite literally - we, as all animals, "learn through play." The primary function of it is to train, especially the young, "to respond to real-life threats and opportunities," at the same time amplifying their sensimotor skills (Collins 2013: 63). Apart from that, play is a perfect context for discharging extra energy that could otherwise lead to actual aggression (e.g. Huizinga 1980: 2); it also serves "relaxation" and satisfies the "imitative instinct" (Huizinga 1980: 2), "establishes dominance ranking"

This is the prevailing view in play studies; however, there has also been some evidence that play has short-term benefits as well, especially for young animals (e.g. Fagen and Fagen 2004). 
in a given group, and "stimulates inventiveness" of its members (Collins 2013: 63).

Although play is a universal among animals, it is not the case that it happens all the time in all the species. It is going to occur only on the condition that the animals engaging in it feel safe. It is going to intensify, in turn, in a population which has the access to an optimum of resources, both in terms of, for instance, food supplies, as well as the evolved repertoire of behaviours adding to their survival success. As Burghardt puts it, when delineating his "theory of surplus resource," play becomes more and more common when a population or a species has "excess resources along with appropriate evolved motivational, physiological, and ecological systems. Play can evolve independently whenever physiological (including neural), life history, metabolic, ecological, and psychological conditions, in conjunction with a species' behavioral repertoire, reach a threshold level" (2005: 172).

All the aforesaid characteristics of play can be summarized in a set of five criteria, which Gordon M. Burghardt provides in his book The Genesis of Animal Play: Testing the Limits. In order to be considered a play, a particular behaviour is to be (1) structurally different from serious behaviour similar to it (2) not fully functional in the context it occurs, (3) voluntary, pleasurable, and/or self-rewarding ${ }^{4}$. Importantly, it is also to be (4) initiated in safety, and (5) occurs repeatedly during an animal's life, or at least some span of it (Burghardt 2005: 382). Summing up, it can be characterised as "repeated behavior that is incompletely functional in the context or at the age in which it is performed and is initiated voluntarily when the animal (or person) is in a relaxed or low-stress setting" (Burghardt 2010: 346).

\section{Importance of Play in Humans}

In his Study of the Play-Element in Culture, Johan Huizinga famously labelled human species Homo Ludens, "Man the Player" (1980). Indeed, it seems that play has had a crucial part in the evolution of human culture. Since, as it has already been stressed, play demands a kind of a double cognition - seeing something as what it actually is, and at the same time seeing it as signifying something else - play seems much connected with the development

4 It is pleasurable and/or self-rewarding, for it increases the ratio of dopamine (the neurotransmitter for motivating and rewarding) produced in the brain (see: Siviy 1998 in Boyd 2009: 93). 
of symbolic behaviour in humans, which is probably most evident when studying play patterns and use of symbols in children (e.g. Roberts and Krause 2002). Play has also been one of the many phenomena that facilitated sociality in our species, as it involves mutual "mind reading" and theory of mind (Collins 2013: 66). Moreover, as Huizinga puts, "play is more than a mere physiological phenomenon or a psychological reflex. It goes beyond the confines of purely physical or purely biological activity. It is a significant function - that is to say, there is some sense to it. In play there is something 'at play' which transcends the immediate needs of life and imparts meaning to the action" (Huizinga 1980: 1).

Indeed, in humans play seems to be of "significant function," which adds up to the fact that they have developed a very wide range of play behaviours, "from doodling when bored to risky adventure play" (Burghardt and Graham 2010: 403). For instance, when writing about children play, Burghardt refers to a 1655 engraving by Jacob Catz and instantly lists a whole spectrum of play scenarios:

Like the famous painting on children's play by Pieter Bruegel, this engraving depicts numerous playful activities spanning the range of the three categories of play in animals: locomotor/rotational play, play with objects, and social play. This figure depicts jumping rope, flying kites, walking on stilts, bowling, playing leapfrog, marching in a band, riding on a hobby horse, playing blind man's bluff, and, in the lower left corner, playing with dolls and kitchen implements. (Burghardt 2010: 340-341)

An interesting stratification of play behaviours in humans, from the most private to the most public, has been provided by Brian Sutton-Smith: (A) mind or subjective play, such as daydreaming, (B) solitary play, such as modelling airplanes or reading, (C) playful behaviours, such as playing tricks, (D) informal social play, including jokes, (E) vicarious audience play: spectator sports or theatre, $(F)$ performance play: playing voices, $(G)$ celebrations and festivals: carnivals, $(\mathrm{H})$ contests: gambling, (I) risky or deep play: skateboarding or sky jumping (1997: 5). Collins, in turn, makes a major distinction between (A) social play, and (B) language play that evolved from social play (2013: 147-148).

What is more, apart from all the possible play forms, there are no boundaries to what can be construed as play: as Sutton-Smith stresses, "[a]lmost anything can allow play to occur within its boundaries, as is illustrated, for example, by works on tourism as play [...], television as play [...], day-dreaming as play [...], sexual intimacy as play [...], and 
even gossip as play" (1997: 3). Apart from developing such a wide range of play scenarios, conventionalising some of them and transmitting from one generation to another (cf. Huizinga 1980: 9-10), humans have also developed a whole repertoire of behaviours accompanying play proper, such as smiling, laughing, or singing (Burghardt and Graham 2010: 407).

\section{Art and Storytelling as Play-Pretend}

The play repertoire of humans seems also to subsume artistic activity. The theory of art as a play - and, specifically, an adaptation which evolved from animal play - has been put forward, for example, by Brian Boyd in On the Origin of Stories. Evolution, Cognition and Fiction (2009: 91). The strong connection between the two behaviours has also been stressed, for example, by Huizinga (1980: 158). The main arguments for anchoring art in play are: (1) art is a universal in all human populations - as Boyd puts it, "[n]o human society lacks art" (2009: 84); (2) engaging in art both on the part of the artist creating a work of art and the audience, those that apprehend (and, possibly, appreciate) that work of art - entails too high costs to and is far too rewarding to be of low adaptive value for the species. In Boyd's words:

If art involved no benefit, if it only mimicked biological advantage, as drugs do, by delivering unearned pleasure, yet it had high costs in time, energy, and resources, then a predisposition to art would be a weakness that would long ago have been weeded out by the intensity of evolutionary competition. (Boyd 2009: 83)

Boyd goes a step further and specifies art as "a kind of cognitive play, the set of activities designed to engage human attention through their appeal to our performance for inferentially rich and therefore patterned information" (Boyd 2009: 85). In other words, art is a patterned practice that - unlike some similar practices in our species - provides us with a cognitively nourishing "open-ended pattern" (Boyd 2009: 89). At this point, Boyd provides the example of William Shakespeare's Henry $I V$ : "[w] respond almost immediately to patterns of characters - Falstaff's shameless exuberant ebullience, Hal's controlled wildness, Hospur's impetuousness, Glendower's impassioned boastfulness, and much more [...]. Patterns set up expectations, which they may satisfy, overturn, or revise" (Boyd 2009: 90-91). 
The example of Henry $I V$ is not incidental in here. As it has been alluded to in the introduction to this paper, one of the behaviours in humans that has been analysed in terms of play patterns, is storytelling - or, more specifically speaking, literature. Interestingly, the connection between storytelling i.e. composing narratives - and animal play has been unintentionally stressed by scholars from outside of evolutionary literary studies. For instance, David Herman, in his entry on "cognitive narratology" in The Living Handbook of Narratology, dwells on one of the fields of research on narratives transmedial studies - as analysing stories across media due to the narrative frame, or "macroframe" that enables recognising them as such (Herman 2011), frames, as we will see in the subsequent section, being an essential element of recognising play as play - and, accordingly, storytelling as storytelling.

As far as language and storytelling practices are concerned, Christopher Collins defines animal play as "a framed, scripted episode within which particular sign values are transformed" (2013: 63). As such, storytelling can certainly be conceived of as a social play (when the storyteller addresses an audience) or a private play (in structural terms probably resembling an object play, in which an individual tells a story to him/herself). In the case of private cognitive-object play, the object is to be a narrative and its material realisation - i.e. language in verbal or, for instance, visual representations in non-verbal narratives.

Storytelling, once understood in terms of play-pretend, can also be linked with certain characteristics of animal play; it is, for instance, a kind of a social display, or a means of establishing dominance rankings. That is true especially about literature, as both writing it as well as reading it expressly "high" works of the canon - boosts social status and is associated with prestige. Also, storytelling - just as animal play in terms of sensimotor skills - hones some of our capacities: in the case of verbal storytelling, it is plausible to think, for instance, of honing language or social competence.

\section{Play Frame}

One of the intuitions about play, based on observation, is that it is "secluded," "limited" (Huizinga 1980: 9), somehow cut off from the rest of the "serious" reality. As Christopher Collins puts it, "[f]or animals, human and nonhuman alike, play has always constituted one recognizable type of extended episode, distinct from the everyday routines of biological maintenance and survival" (2013: 63). This episode occurs only within a certain cognitive frame, in which the usual reasoning is restrained by particular play-rules (Huizinga 
1980: 152). The question is, then, how do animals know that it is the playrules that they should abide by at a particular point? Or, to use Bekoff and Byers' words: "How do animals read play intention in conspecific?" (Bekoff and Byers 1998: xvi). How do they know that what is about to happen should involve not single, as usual, but double cognition? An interesting model has been proposed by Gregory Bateson, according to whom play is preceded by a pre-play exchange (Bateson 1972: 185). Such an exchange usually takes the form of "metacommunication," employing "signals which would carry the message "this is play" (Bateson 1972: 185).

A metacommunication signal invites "the addressee to enter into what Bateson called a 'play frame', [...] within which actions (e.g. chasing, nipping, and sparring) would not indicate that sort of hostility that might otherwise lead to injury or death" (Collins 2013: 65). In terms of semiotics, a metacommunication signal is, then, a kind of a pre-index subverting the meaning of all the signals that follow ${ }^{5}$.

Apart from pre-play exchange, signals can also be cued during the play as such, especially when the play intention is misinterpreted or the play frame is apt to collapse; then, metacommunication signals serve to maintain the frame and reassure the co-player that whatever happens is not "serious" (cf. Bekoff 1995).

Metacommunication seems especially significant in the case of social play. As Burghardt and Graham point,

Maintaining social play requires that players be highly attuned to the rapidly changing nature of the play bout. Players must read social cues appropriately, react swiftly and accurately to movements, and anticipate responses. Hence, play signals have evolved in many species that act as behavioral cues or honest reassurances that the behavior is playful. Typical play signals include play bows in canids and open-mouthed play faces in primates and carnivorans. (Bekoff 1975; Pellis and Pellis 1996 In Burghardt and Graham 2010: 395).

5 As Collins notes, "[i]n semiotic terms, the metacommunication is a preliminary index that negates in advance all subsequent indices of [for instance] aggression [...] and transforms them into mutually recognized icons of [for instance] aggression" (Collins 2013: 66) - indexical communication that precedes the act of play; such an episode means "I invite you to enact with me a script in which what we two do will indicate aggression but not lead to injury, because we agree that it merely looks as though it indicates it" (Collins 2013: 66). 
The ability to read these "social cues" translates onto something of a play competence of an individual. These, together with the play patterns themselves, can - and in humans certainly do - become conventionalised and transmitted (Huizinga 1980: 9-10).

The "social cues" for play most thoroughly described in literature include vocalisations observed in many fissiped carnivorans, such as chirrups in rats (e.g. Knutson et al. 1998 In Burghardt and Graham 2010: 407). Vocalising is not, however, the only way to signal play intention. In order to signal and maintain social play, canids, for instance, bow during play sequences (Bekoff 1995). Just as play in itself can be covert (cf. Burghardt 2010: 351), there are also other, more covert strategies for signalling and maintaining a play frame. In canids, in a R\&T play, bites that are too gentle to hurt are an instant indicator that the rough-and-tumble is not for real (Bekoff 1995). In humans, these can include, for instance, smiling or laughing (cf. Burghardt and Graham 2010: 407). It is also vital to acknowledge the fact that although play as such is always volitional, a metacommunication signal does not necessarily need to be conscious (Bateson 1972: 185).

What is also important, as Collins remarks, it is only in social play, i.e. play in which there are two or more participants, that a metacommunication signal is necessary (2013: 65). It does not mean, however, that in the case of an individual involved in an object or locomotor play on their own, there is no need for demarcating the play frame. In such a situation, the play frame is still being secured; it is just that the signal for it is issued within the cognitive apparatus of the one and only player and, clearly, it does not need to be transmitted to the outside.

Yet another possible problem about determining a play frame is that play does certainly contain a very strong subjective component: as, for example, Burghardt stresses, play is play when the players (or the observers) subjectively identify it as such (2005: 14).

\section{Framing Narratives}

Assuming that storytelling is anchored in play (cf. Boyd 2009; Collins 2013), the same processes of exchanging a metacommunication signal and only then engaging in play-pretend should apply to narratives ${ }^{6}$. For the purposes of this

6 For the sake of disambiguation, I would like to briefly define what is herein understood by "a story" and "a narrative," since the two are sometimes used interchangeably, although they are only partial synonyms (Ryan 2007: 22). A story is a conceptualised chrono- 
paper, I define a narrative after the founding father of narratology, Gérard Genette, as of threefold meaning: (1) "the narrative statement, the oral or written discourse that undertakes to tell of an event or a series of events," (2) "the succession of events, real or fictitious, that are the subject of this discourse," and (3) "an event: not, however, the event that is recounted, but the event that consists of someone recounting something: the act of narrating taken in itself" (Genette 1980: 25-26). The meaning of a narrative, as understood herein, can be then comprised in David Herman's unpretentious definition as conveying a story to somebody else in a manner different from description (Herman 2007: 8-9).

As Aristotle famously stated in Poetics, a narrative needs to have a "beginning, middle, and end" (Aristotle in Richardson 2002: 2; Collins 2013: 63). Applying that to the study of storytelling as play, Collins remarks: "Whatever I happen to do before I start and after I end frames this activity, which, while I am doing it, constitutes a particular routine, or "script"' (2013: 63). How is such a frame founded?

An interesting procedure has been unintentionally described by Arthur W. Frank, who in order to verify whether a given account had a potential to be a story, decided to tell it to his daughters in a "bedtime test": As he notes,

If a self-respecting six- or eight-year old asks for a story before bedtimes, would she or he accept this as a story? Some narrations that are surprisingly close to Tilly's technical accounts might pass the bedtime test. My younger daughter used to ask for a story about how dinosaurs became extinct [...]. My best guess is that the narrations qualified as bedtime stories because they aroused a sufficient degree of imagination. My daughter could imagine the earth growing darker after being struck by a meteor, dust filling the air, food growing scarce... (Frank 2010: 41-42)

In this case, it seems important that the storyteller has been asked for telling a story. Such a request automatically sets the ground for a play frame. But there are many types of narratives, and each of them may require a different framing design.

logical sequence of events incorporating an agent (or agents), a spatial and a temporal dimensions. Once a story, as something conceptual, is transmitted - via any medium - it is automatically composed into a narrative. Thus, "a story" and "a narrative" can be used interchangeably only when to designate "storytelling" as "composing narratives" (cf. Abbott 2007). 
First of all, the design differs, as we distinguish between narratives that we tell others and narratives that we tell to our own selves. As Marie-Laure Ryan points, referring to psychologist Jerome Bruner and philosopher Galen Strawson, we all incessantly work on "an internal autobiography," organising our lives as stories, and also making sense of the outside world in our private narratives (Ryan 2009: 310). In this sense - the context of privacy or seclusion - private narratives resemble more of an object play than a social play. An individual creates his/her own play frame and fills it with a story similarly to a cat playing with a yarn ball. Public narratives, on the other hand, are a social play proper, i.e. they engage more than one player (cf. Ryan 310311). Apart from literature - i.e. verbal, literary narratives - public narratives include, for instance, conversational storytelling. As Neal R. Norrick notes, "[w]e tell stories to make a point, to catch up on each other's lives, to report news, and to entertain each other" (2007: 127). We also narrate in the public to back up our beliefs and norms, adding up to ideologies (see, e.g.: Barthes 1977a; Herman and Vervaeck 2007), or tell bedtime stories to children (e.g. Frank 2010: 41).

Second, narratives can be classified on the basis of the medium they use. Each medium, from oral or written text to visual forms, including film or mime, enables and depends upon different strategies for establishing a play frame. And there are also different narrative genres (e.g. Herman 2002: 91), such as a fairy tale or a detective story ${ }^{7}$, all built around distinct conventions. And, again, each convention calls for a compatible framing. Characterising framing narratives is, then, at least as complicated as providing a taxonomy of all the narrative media, types, genres and sub-genres.

The major difference in all the narrative frames depends, to a great extent, on the kind of metacommunication signal sent. In the case of private narratives, just as in an individual object play, founding a play frame does not need to be communicated to the outside; the metacommunication signal if it is issued at all - is, then, circulated within the player's own cognitive apparatus. A metacommunication signal proper occurs in public narratives, though. Such signals can include, for instance, conventionalised phrases, such as "Let me tell you a story" in the case of a conversational narrative, or "Once upon a time" in the case of a fairy tale.

Narratives have also been studied as applicable not only to art of literature, but also historical sciences, psychology, psychoanalysis, philosophy, pedagogy, law studies, or medicine (Meuter 2011). In fact, the term "a narrative" has been the object of interest of so many disciplines (cf. Herman 2007: 4) that it has developed most surprising sub-types, such as, for instance, "illness narrative": a concept from psychology and sociology, see, for example: Douglas Ezzy (2000) or Mike Bury (2001). 
These are quite overt signals; but the metacommunication signal does not need to be direct, as in "This is play" example used by Bateson (1972). The signal establishing a play frame for a narrative can be more covert than a simple "A Short Story" or "A Novel" following the title. The more the audience or the readers are familiar with the medium and the kind of language used for a particular narrative - in other words, the higher their narrative and play competence is - the more they are likely to recognize even implicit signals. Such covert signalling can comprise, for example, the use of a play-based device of an allegory or a symbol: e.g. a personified animal from a fairy tale standing for a particular type of a person. As long as the audience is able to recognise it as a play device, they are also able to recognise the whole of the piece as framed for play.

This can be best seen once the audience actually fails to identify the covert metacommunication signalling and subsequently does not recognise the play frame. In Storytelling and the Sciences of Mind, David Herman alludes, though in a different context, to the famous incident when Orson Welles's adaptation of H. G. Wells's The War of Two Worlds (1898) was broadcasted on the radio. The account of Martians invading the Earth induced an actual outburst of panic among the audience. Sometimes, as Jonathan Gottschall stresses, "[p]retend play is deadly serious fun" (2012: 32). Especially, when the players do not know they are playing. As Herman notes, the broadcast was on Halloween, which would make it plausible to presume it was all a prank; what is more, it was taken seriously "despite the announcer's opening reference to Wells's novel and despite the action being set one year in the future, in 1939" (Herman 2013: 8). However, there were people who - probably due to their high play competence or what we would conventionally call just "common sense" did not take the war of two worlds seriously: for instance, Herman's grandfather, when listening to the broadcast, mindfully concluded that if it was true, it would be on all the radio channels, and not just one (Herman 2013: 9).

It seems that in narratives, apart from being fairly covert, such framing can also be delayed. It may be the case that the convention - and thus the play frame - is not at once recognisable. It is but after a couple of pages that the reader recognises play elements in the text, such as the use of a poetic device, and only then does the play proper commence. It is also after a couple of pages that the reader notices yet another metacommunication signal characteristic of storytelling play-pretend: a purposeful anachrony in the plot, i.e. a discrepancy between the order of events in the story and the order in which they are presented in a narratives (cf. Genette 2002: 26). 
Such a discrepancy is characteristic of narratives and does not occur, for instance, in descriptions (cf. Abbott 2011).

Framing depends also on media and conventions for narratives that are frames in themselves. Coming back to Huizinga's point on ritualising and transmitting play patterns and metacommunication signals for them, we can claim that some types of narratives have been used and re-used in the course of human history, accordingly creating schemas that have been culturally transmitted. Thus, when we, for instance, go to a cinema, the schema for this ritual itself is an index for play. We know what to expect: we know we will see a visual narrative of one genre or another.

\section{Conclusion}

As is evident from the above, establishing a play frame in the case of narratives depends on a number of factors, from the medium to the particular devices used. Importantly, it seems that metacommunication signals in narratives can, for the most part, be found at a metanarrative level. The higher the narrative competence of the players is then, the more covert the signalling can be. There is still much to be specified with reference to storytelling as play. This paper is of fairly theoretical character; its primary aim has been, however, to point to the fact that modelling human storytelling activities as cognitively anchored in animal play is by no means the end of the story. It seems that framing a narrative as a complex cultural construct demanding double cognition is just as complicated as the routines for signalling play in animals. As Bekoff analysed play signalling in canids and provided an in-depth description of the intensity and rates of bows that establish and reassure play frames in the species, it is perhaps just equally possible to observe, measure, and empirically test the different play frame designs that humans use while telling stories. This - and much more relevant research - still seems a work in progress, though.

\section{References}

Abbott, H. P. (2011). Narrativity. In P. Hühn et al. (Eds.) The Living Handbook of Narratology. http://www.lhn.uni-hamburg.de/article/narrativity. DOA: 30 Nov. 2015.

Abbott, H. P. (2007.) Story, Plot, and Narration. In D. Herman (Ed.) The Cambridge Companion to Narrative. Cambridge: Cambridge University Press, 39-51. 
Barthes, R. (1977a). Introduction to the Structural Analysis of Narratives. In R. Barthes. Image-Music-Text. London: Fontana Press, 79-124.

Bateson, G. (1972). Steps to an Ecology of Mind. Collected Essays in Anthropology, Psychiatry, Evolution, and Epistemology. London-Northvale, New Jersey: Jason Aronson Inc.

Bekoff, M. and J. A. Byers (Eds.) (1998). Animal Play: Evolutionary, Comparative and Ecological Perspectives. Cambridge: Cambridge University Press.

Bekoff, M. (1995). Play Signals as Punctuation: The Structure of Social Play in Canids. Behaviour 132, 419-429.

Boyd, B. (2009). On the Origin of Stories. Evolution, Cognition, and Fiction. Cambridge, Massachusetts-London, England: The Belknap Press of Harvard University Press.

Burghardt, G. M. and K. L. Graham. (2010). Current Perspectives on the Biological Study of Play: Signs of Progress. The Quarterly Review of Biology 85(4), 393-418.

Burghardt, G. M. (2010). The Comparative Reach of Play and Brain. Perspective, Evidence, and Implications. American Journal of Play 2(3), 338-356.

Burghardt, G. M. (2005). The Genesis of Animal Play: Testing the Limits. Cambridge, MA: MIT Press.

Collins, Ch. (2013). Paleopoetics. The Evolution of the Preliterate Imagination. New York: Columbia University Press.

Frank, A. W. (2010). Letting Stories Breathe: A Socio-Narratology. ChicagoLondon: The University of Chicago Press.

Genette, G. (2002). Order, Duration, and Frequency. In B. Richardson (Ed.) Narrative Dynamics: Essays on Time, Plot, Closure, and Frames. Columbus: The Ohio State University, 25-34.

Genette, G. ([1930] 1980). Narrative Discourse. An Essay in Method. New York: Cornell University Press.

Gottschall, J. (2012). The Storytelling Animal. How Stories Make Us Human. Boston-New York: Mariner Books.

Heinrich, B. and R. Smolker. (1998). Play in Common Ravens (Corvus Corax). In M. Bekoff and J. A. Byers (Eds.) Animal Play: Evolutionary, Comparative and Ecological Perspectives. Cambridge, UK: Cambridge University Press, $27-44$.

Herman, D. (2013). Storytelling and the Sciences of Mind. Cambridge, MassachusettsLondon, England: The MIT Press.

Herman, D. (2011). Cognitive Narratology. In P. Hühn et al. (Eds.) The Living Handbook of Narratology. http://www.lhn.uni-hamburg.de/article/cognitivenarratology-revised-version-uploaded-22-september-2013. DOA: 30 Nov. 2015.

Herman, D. (2007). Introduction. In D. Herman (Ed.) The Cambridge Companion to Narrative. Cambridge: Cambridge University Press, 3-21.

Herman, D. (2002). Story Logic: Problems and Possibilities of Narrative. Lincoln: University of Nebraska Press. 
Herman, L. and B. Vervaek. (2007). Ideology. In D. Herman (Ed.) The Cambridge Companion to Narrative. Cambridge: Cambridge University Press, 217-230.

Huizinga, J. (1980). Homo Ludens. A Study of the Play-Element in Culture. LondonBoston-Henley: Routledge \& Kegan Paul.

Meuter, N. (2011). Narration in Various Disciplines. In P. Hühn et al. (Eds.) The Living Handbook of Narratology. http://www.lhn.uni-hamburg.de/article/ narration-various-disciplines. DOA: 30 Nov. 2015.

Mitchell, R. W. (Ed.) (2002). Pretending and Imagination in Animals and Children. Cambridge-New York: Cambridge University Press.

Norrick, N. R. (2007). Conversational Storytelling. In D. Herman (Ed.) The Cambridge Companion to Narrative. Cambridge: Cambridge University Press, 127-141.

Richardson, B. (Ed.) (2002). Narrative Dynamics: Essays on Time, Plot, Closure, and Frames. Columbus: The Ohio State University.

Roberts, W. P. and M. A. Krause. (2002). Pretending Culture: Social and Cognitive Features of Pretense in Apes and Humans. In R. W. Mitchell (Ed.) Pretending and Imagination in Animals and Children. Cambridge-New York: Cambridge University Press, 269-279.

Ryan, M. L. (2009). Narrativity and its Modes as Culture-Transcending Analytical Categories. Japan Forum 21(3), 307-323.

Ryan, M. L. (2007). Toward a Definition of Narrative. In D. Herman (Ed.) The Cambridge Companion to Narrative. Cambridge: Cambridge University Press, 22-35.

Sutton-Smith, B. (1997). The Ambiguity of Play. Cambridge, MassachusettsLondon, England: Harvard University Press. 